University of Nebraska - Lincoln

DigitalCommons@University of Nebraska - Lincoln

April 1996

\title{
Improved conversion of plant oils and animal fats into biodiesel and co-product
}

Praveen R. Muniyappa

Department of Chemical Engineering, University of Nenraska-Lincoln

Scott C. Brammer

Department of Chemical Engineering, University of Nebraska-Lincoln

Hossein Noureddini

Department of Chemical Engineering, University of Nebraska-Lincoln, hnouredd@unlnotes.unl.edu

Follow this and additional works at: https://digitalcommons.unl.edu/chemeng_biomaterials

Part of the Biomaterials Commons

Muniyappa, Praveen R.; Brammer, Scott C.; and Noureddini, Hossein, "Improved conversion of plant oils and animal fats into biodiesel and co-product " (1996). Papers in Biomaterials. 20.

https://digitalcommons.unl.edu/chemeng_biomaterials/20

This Article is brought to you for free and open access by the Chemical and Biomolecular Engineering Research and Publications at DigitalCommons@University of Nebraska - Lincoln. It has been accepted for inclusion in Papers in Biomaterials by an authorized administrator of DigitalCommons@University of Nebraska - Lincoln. 


\section{Abstract}

Increased environmental awareness and depletion of resources are driving to develop alternative fuel from renewable resources that are environmentally more acceptable. Esters of fatty acids (biodiesel, derived from the transesterification vegetable oils, have properties similar to components of peh-oleior. based diesel fuel Cost has been a major factor slowing the commercialization of biodiesel Glycerol is the coproduct of the esterification process. In this work the feasibility of the glycerol of vegetable oil. with crude glycerol derived from the transesterification of the vegetable oils and animal fats was studied. Utilization of the crude co-product of the biodiesel process was investigated for improving the overall economy The transesterification of soybean oil for fuel purpose was optimized. Optimization results are presented. transesterification of beef tallow produces a mixture of esters which is more concentrated in the saturated fatty acids. Physical properties of these esters are similar to esters of soybean oil. Reaction results and properties for beef tallow are presented.

Key words: Biodiesel, renewable fuel; triglycerides, glycerol; tallow, soybean oil.

\section{INTRODUCTION}

Increased environmental concerns, tougher Clean Air Act standards, and depletion of raw material petroleum feedstock) are-e driving industry to come up with viable alternative fuels that burn more cleanly. a field in which vegetable oils and animal vegetable oils is hardly new. Vegetable oils have been considered as fuel for diesel engines since the earliest days of the compressionignition engines. Rudolph Diesel. the inventor of the compression ignition engines, used peanut oil 
in a 1900 demonstration. While short-term tests are almost always positive (e.g. Mazel er al.; 1585; Samson et al., 1585); long-term use of neat vegetable oils leads to severe engine problems, such as deposition, ring sticking, and injector coking (Peterson et ol.; 1581). High viscosity and a tendency for polynierization within the cylinder appears to be at the root of many problems associated with direct use of these oils as fuels (Ryan 111 et al._ 1984; Peterson, 1986). Fatty esters (biodiesel) from vegetable oils and animal fats have shown promise as alternative diesel fuels as a result of improved viscosity and volatility relative to the triglyceride (Clark et al.; 1984). This has stimulated interest in optimization of transesterification reaction conditions. The esterification process involves the transformation of the large, branched, triglyceride molecules of bio-oils and fats into smaller, straight-chain molecules, similar in size to components of diesel fuel (Scheme 1). A dense, liquid phase rich in glycerol is the co product of this process. The transesterification process (also called alcoholysis) has been intensively patented as widening industrial uses were found for ester-s (e.g. Tanaka et al.; 1581; Sankaran, 1990; Meffel- t: 1584 Freemen cr al.: 1984). The chemical and physical properties of biodiesel closely resemble those of diesel fuel. This has been documented by many workers (e.g. Clark et al.. 1984: Mittelbach Tritthart, 1988). Biodiesel cetane number, energy content. viscosity and phase changes are similar to those of petroleum-based diesel fuel. Moreover, biodiesel is essentially sulfur free. Engines fueled by biodiesel emit significantly fewer particulates, hydrocarbons, and less carbon monoxide than those operating on conventional diesel furl. Emissions of NO,s, however, are slightly higher than those of diesel engines operating on conventional diesel fuels (Mittelbach \& Tritthart, 1988). Biodiesel also offers enhanced safety characteristics when compared to diesel fuel. It has a higher Rash point and does not produce explosive air fuel vapors. Moreover, it is biodegradable, less toxic; and, compared to petroleum fuel. biodiesel emissions from an engine operating on these fuels are less toxic due to an absence of aromatic hydro 
carbons. The esterified vegetable oils have a higher cloud point than diesel fuels and require engine and fuel heaters when used as a pure fuel in climates where the temperature dips below VC. However, for a $20-25 \%$ blend of the esterified oil and petroleum based diesel, no heater is required (from about -10 to $15^{\circ} \mathrm{C}$ ). Cloud point suppressants may also be used to eliminate this problem. While biodiesel fuels have been around since World War 11; their high cost has been a major obstacle for commercialization. Their current role in the market place is largely tied to environmental concerns and the more stringent government standards. This may change if the crude glycerol co-product from the transesterification process is utilized for production of derivatives of glycerol, such as mono- and diglyceride. Glycerolysis of vegetable oils or animal fats produces a mixture of monoand diglyceride which are valuable chemical intermediates. The conventional glycerolysis process has been investigated and patented by many workers (e.g. Rheineck et al., 1968; Sonntag. 1982; Alsop et al., 1963; Birnbaum, 1959; Birnbaum \& Lederer, 1963; Kuhrt, 1953). In this work the feasibility of the glycerolysis of vegetable oils with crude glycerol derived from the transesterification of vegetable oils and animal fats was studied. The transesterification of soybean oil for fuel purposes was optimized. Beef tallow was studied as the raw material for biodiesel and some physical properties of methyl tallowates were measured. 


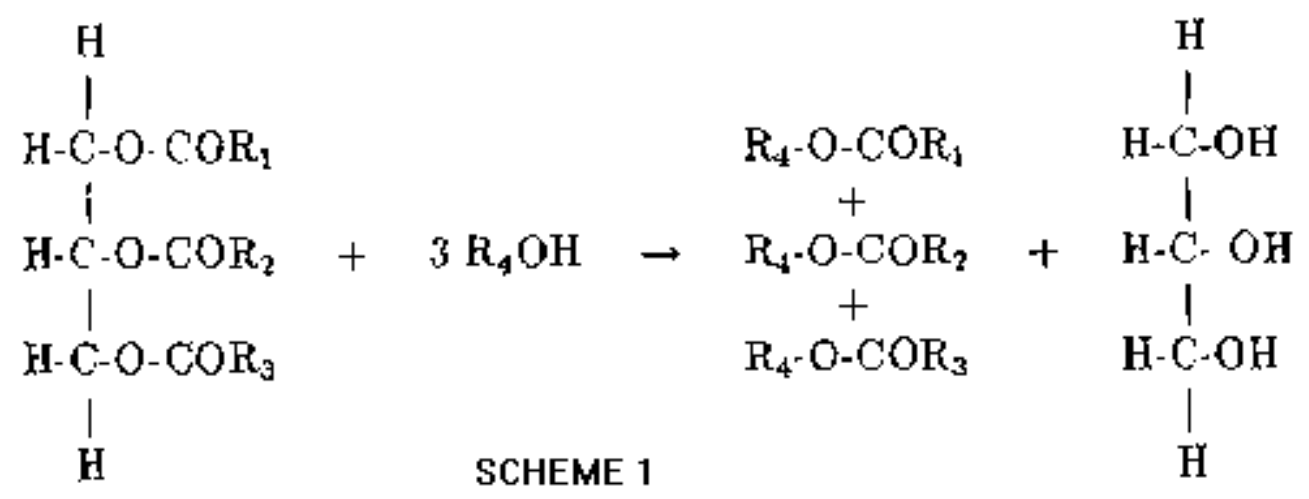

\section{METHODS}

\section{Transesterification of triglycerides}

Although the transesterification of vegetable oils or animal fats can be done in an unsophisticated process, the process conditions must be carefully controlled and or modified to achieve maximum yield $(98 \%)$ at the lowest temperature and reaction time. In the conventional transesterification reaction the reactor is initially charged with vegetable oil or animal fat, methyl alcohol in an amount of 2-10 equivalents, and sodium hydroxide catalyst in an amount $0.1-1.0 \mathrm{wt} \%$ by weight based on the free fatty acid concentration of the glycerides. The reaction mixture is then heated to the boiling temperature of methyl alcohol and refluxed for about an hour under agitation. The reaction is at atmospheric pressure and methyl alcohol vapors condense at about $68-70^{\circ} \mathrm{C}$. A conversion of $90-99 \%$ is usually obtained to form a blend of fatty esters. With the agitation stopped, the reaction mixture will separate into an upper layer of methyl esters and a lower layer of glycerol diluted with unreacted methyl alcohol. The fatty ester product in the upper layer should be further neutralized and vacuum distilled for removal of excess alcohol before use as fuel. In a two-stage process, the upper layer of methyl esters product obtained in the first stage is further admixed with additional 
IMPROVED CONVERSION OF PLANT OILS AND ANIMAL FATS INTO BIODIESEL AND CO-PRODUCT methyl alcohol in an amount of 0.75 equivalents. The mixture undergoes a second transesterification reaction similar to the first stage for $30 \mathrm{~min}$.

\section{Beef tallow}

Experimental investigations for the transesteritication of beef tallow were performed according to the above procedure. Results of a few representative experiments are tabulated in Table 1 , based on high pressure liquid chromatography analysis. The results reveal that high conversion of triglycerides to fatty acids may be achieved in a one-stage process. High- purity fatty esters may be prepared in a two-stage process at a considerably lower yield due to more losses in the processing and to reverse reactions. The results are also indicative of a diverse effect of moisture on the conversion, which is consistent with the work of previous investigators (e.g. Wright et al., 1944). Unlike vegetable oils; beef tallow's transesterification tends to form a gel-like material in some experimental runs. A high concentration of saturated fatty acid components in beef tallow, poor agitation, and low conversion of triglycerides are suspects for this phenomenon. Incomplete reactions and or reverse reactions result in formation of mono-: di-. and even triglycerides with relatively high melting points. These will simply form a solid or gel-like phase. Density, viscosity and cloud point of methyl esters made from the transesterification of beef tallow are presented in Table 2. Properties of soybean oil esters and petroleum-based diesel fuel are included for comparison. The high cloud point of methyl esters, particularly those from beef tallow, is indicative of a high concentration of saturated fatty esters. This is a major concern for their utilization as diesel fuel. A higher concentration of unsaturated fatty acids in soybean oil is responsible for the lower cloud point of these esters. The degree of homogeneity (emulsification) of alcohol in the triglyceride phase is of great importance in the transesterification process. In conventional alcoholysis these factors are induced through mechanic 
cal mixing and increasing the temperature of the reactor. Because of its high melting point and higher viscosity. This effect is particularly important to the transesterification of tallow.

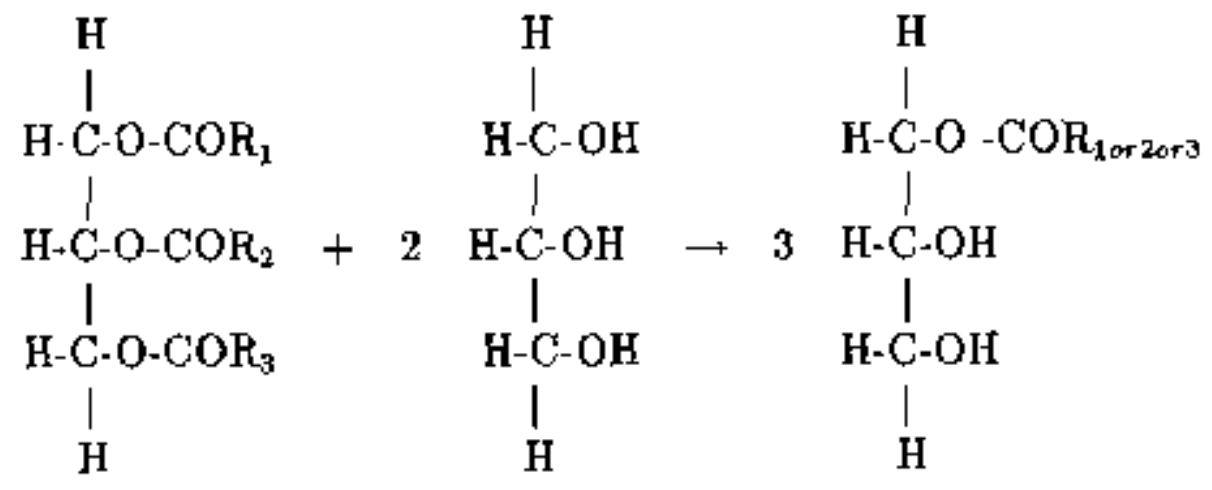

SCHEME 2

Table L. Transesterificalion reaction results for beef tallow

\begin{tabular}{|c|c|c|c|}
\hline wt\% Catalyst & Reaction time (h) & No. of stages & Yield (\%) \\
\hline $\begin{array}{l}0.8^{\alpha} \\
1.35^{\sigma} \\
0 \cdot 75 \\
1.40^{\circ} \\
2 \cdot 05^{\alpha} \\
1 \cdot 0 \\
1.0^{\alpha} \\
0.33 \\
0.42 \\
0.52 \\
0.53 \\
0.61\end{array}$ & $\begin{array}{l}1-5 \\
1-5 \\
1.5 \\
1-5 \\
1-5 \\
2-0 \\
2-0 \\
1.5 \\
1.5 \\
1.0 \\
1.5 \\
1.5\end{array}$ & $\begin{array}{l}\frac{2}{2} \\
2 \\
2 \\
\frac{2}{2} \\
1 \\
1 \\
1 \\
1 \\
1 \\
1\end{array}$ & $\begin{array}{l}75-0 \\
78-5 \\
83-1 \\
74-6 \\
73-9 \\
81-4 \\
80 \cdot 0 \\
950 \\
980 \\
96 \cdot 2 \\
97-0 \\
905\end{array}$ \\
\hline
\end{tabular}

BASED ON A $50 \%$ NaOH SOLUTION. ALL OTHERS ARE SOLID NaOH.

\section{Soybean oil}

Transesterification of soybean oil has been extensively investigated by many workers (e.g. Tanak et al., 1981; Sankaran, 1990; Freemen et al., 1984). Therefore, the optimization studies focused primarily on the factors which are of importance to the fuel end users. The experiments were performed in a I 1 flask with a mechanical stirrer and a total condenser open to the atmosphere. A single-stage process which was outlined earlier was used. Alcohol (methanol) was used at about 10 
times the stoichiometric ratio. The soybean oil which was used in the experiments had an acid value of less than 0.05 . The esters of fatty acids derived from the transesterification process must be washed from the excess catalyst (sodium hydroxide) before they are used as fuel. The optimization of the process parameters, therefore, concentrated on reaction time and catalyst concentration. Total conversion of the triglycerides to esters was the basic criterion for the optimization analysis. The objective was to reduce the reaction time and the catalyst concentration without a significant reduction in the total conversion of the triglycerides. The concentration of the catalyst was the first parameter which was studied. Figure 1 reveals that the reduction in the catalyst concentration from 0.5 to $0.05 \mathrm{wt} \%$ had no significant effect on the conversion of the triglycerides. All reactions were allowed 90 min of reaction time. Due to the variations in the free fatty acid content of various vegetable oils, the concentration of the catalyst was not lowered below $0.05 \mathrm{wt} \%$. Free fatty acids up to $0.35 \%$ will be neutralized at this level of catalyst. The Process was then optimized for the reaction time at the lower end of the range for the catalyst concentration. The results are presented in Fig. 2 . The results show that at $0.10 \mathrm{wt} \%$ catalyst concentration the reduction of the reaction time from 90 to $5 \mathrm{~min}$ had no significant effect on the conversion of the triglycerides. Reaction times below 5 mill resulted in some unreacted triglycerides. Optimization studies concluded that high conversion (98\%) of triglycerides to methyl esters may be achieved at $0.10 \mathrm{v} . \mathrm{T} \%$ catalyst after $5-10$ min of reaction time. The presence of catalyst (sodium hydroxide) in methyl esters is not desirable. Utilization of such methyl esters as fuel will pose corrosion problems in the engine. The presence of unused catalyst in the products of the transesterification process was identified by their $\mathrm{pH}$ number. Both the ester-rich layer and the glycerol-rich layer had measured $\mathrm{pH}$ values which were indicative of a basic medium. The results are shown in Fig. 3 and Fig. 4 . The reduction in the percent catalyst used had a significant effect on the $\mathrm{pH}$ value of the ester phase. The effect of the catalyst concen 
tration on the glycerol phase was slight. Neutralization andlor washing may still be necessary for total removal of the catalyst from the product.

PHYSICAL PROPERTIES FOR ESTERS OF TALLOW, SOYBEAN OILS AND DIESEL FUEL.

\begin{tabular}{lccc}
\hline Physical property & Beef tallow esters & Soybean oil esters & Diesel fuel $^{\sigma}$ \\
\hline Density (g/ml) at $40^{\circ} \mathrm{C}$ & $0 \cdot 856-0.859$ & $0.866-0.869$ & 0.835 \\
Viscosity (cP) at $40^{\circ} \mathrm{C}$ & $3.75-3.99$ & $370-3.90$ & $2 \cdot 63$ \\
Clond point ( ${ }^{\circ} \mathrm{C}$ ) & $10-12$ & -1 to & -19 to -15 \\
\hline
\end{tabular}

AUSTRALIAN AUTOMOIWE DIESEL DISTILLATE

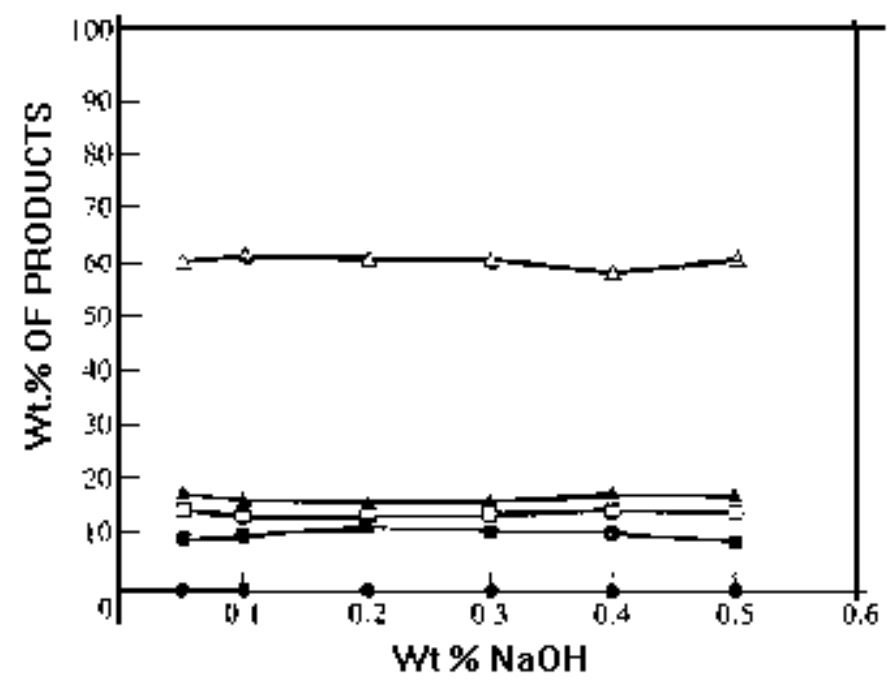

Figure 1: Effect of catalyst concentration on the transesterification products of soybean oil, subject to 90 min of reaction time ( $\mathbf{\square})$, methyl linolenate $(\square)$, methyl palmitate $(\Delta),(\boldsymbol{\Delta})$ mythyl oleate, and triglycerides $(\bullet)$. 


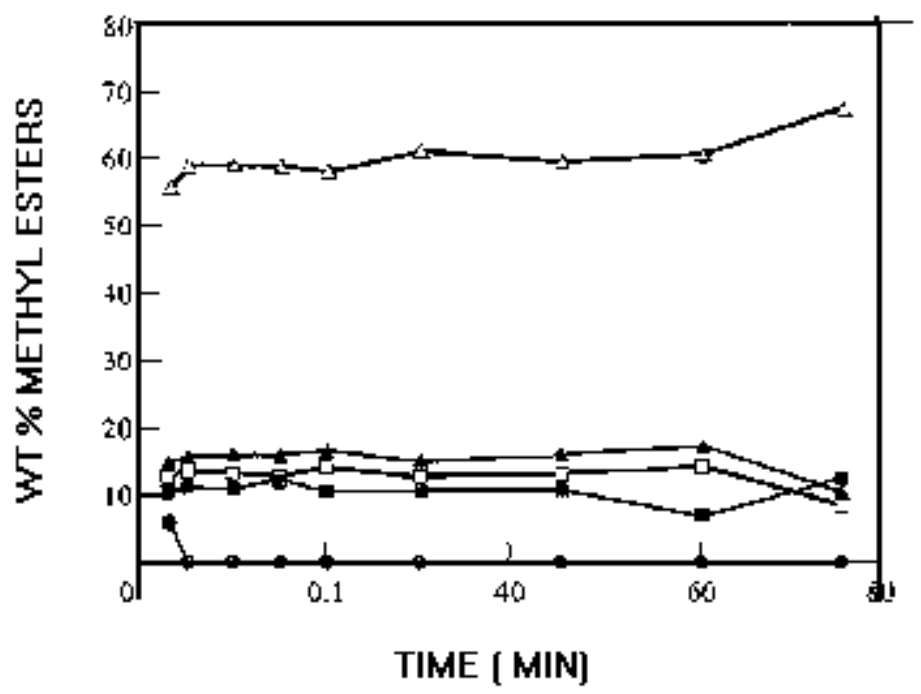

Figure 21: Effect of time catalyst concentration on the transesterification products of soybean oil, subject to $0.1 \mathrm{wt} \%$ of catalyst ( $\bullet)$, methyl linolenate $(\square)$, methyl palmitate $(\Delta),(\boldsymbol{\Delta})$ mythyl oleate, and triglycerides $(\bullet)$.

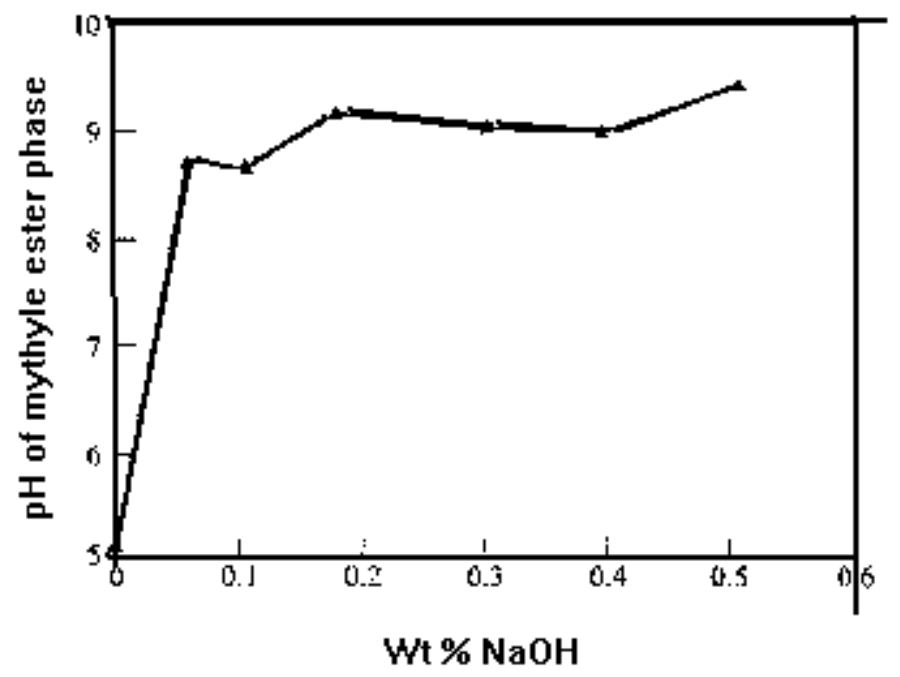

Figure 3 :Effect of catalyst on $\mathrm{pH}$ of the methyl ester rich layer for the transesterification of soybean oil, subject to 90 min of reaction time. 


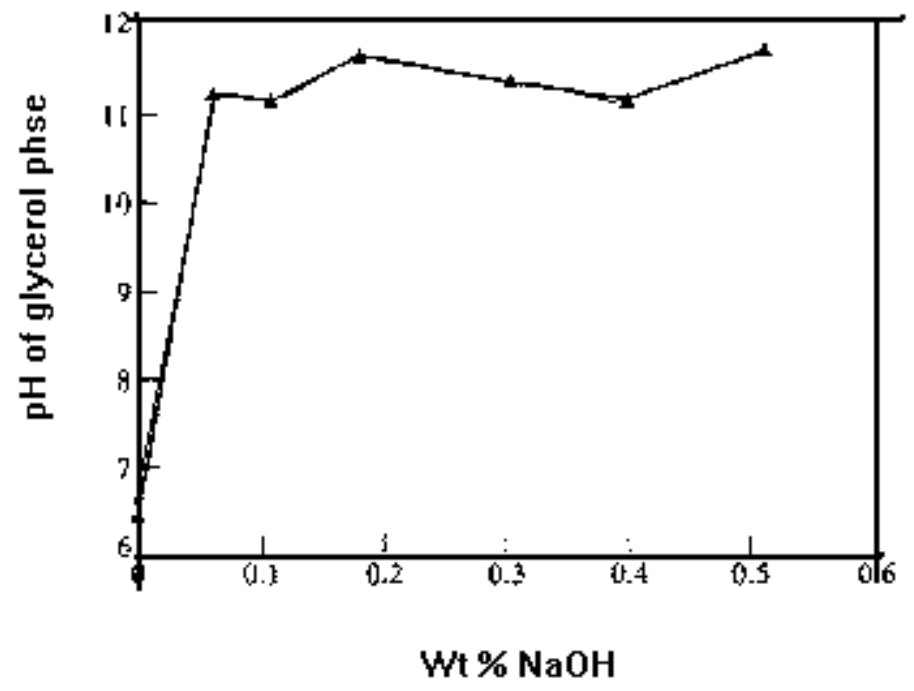

Figure 4. Effect of catalyst on $\mathrm{pH}$ of the glycerol -rich layer for the transesterification of soybean oil, subject to 90 min of reaction time.

\section{Glycerolysis}

Glycerolysis is the transesterification of glycerol with triglycerides to monoglycerides (Scheme 2). XMonoglycerides are the main product of the reaction. However, diglycerides and p-monoglycerides do occur in every glycerolysis reaction. In the conventional glycerolysis reaction, the reactor is initially charged with triglyeerides, about $25-40 \%$ of its weight of glycerol, and $0.05-0.20 \%$ of an alkaline catalyst, preferably anhydrous sodium hydroxide or potassium hydroxide. Then, the charge is rapidly heated under reduced pressure, to remove airl and to protect from oxidation. The reactants are further protected from oxidation by blanketing the reactor with an inert gas, such as nitrogen. The reaction temperature is carried to a maximum of $250^{\circ} \mathrm{C}$ and the reaction is completed in 15 min. The reaction mixture is rapidly cooled to minimize the reversion of the monoglycerides. The un 
reacted glycerol is separated by gravity layer separation or vacuum distillation and recycled back into the reaction vessel. The crude ester layer is a mixture of mono- and diglycerides. Monoglycerides may be separated from this mixture by vacuum distillation. One of the most important factors in the glycerolysis process is the solubility or the degree of contact between the triglycerides and glycerol. The catalyst used in glycerolysis reacts with triglycerides to form soap. which promotes the reaction, at least in part, acting as an emulsifier for glycerol in the fat or oil phase. Similarly, the increase in the temperature aids in the mass transfer of the triglyceride to the glycerol phase and to a faster rate of reaction by increasing the mutual solubility of the fat and glycerol phases. Due to the decomposition of some fatty acids at high temperatures, an upper limit exists for the temperature $\left(250^{\circ} \mathrm{C}\right)$. Thermal instability is caused by heat-sensitive double bonds in the carbon chain. It has long been believed that the reaction temperature, or rather the solubility of glycerol in the triglyceride at the reaction temperature. is the determining factor for the yield of monoglycerides. Sonntag (1982) has reported a high yield of monoglycerides in the glycerolysis reactions under distinct conditions ranging from fine dispersion to super emulsion. For an average particle size of 0.05-10 microns and smaller, yields of $61-95 \%$ for monoglycerides are reported (Sormtag, 1982). In all cases examined, the fat and glycerol phases are still heterogeneous, although homogeneity is approached at the super emulsion range. Sonntag concludes that high temperature and solubility may not be the only conditions necessary for a high yield of monoglycerides. A high degree of contact may also be a feasible path to high conversion of fats and glycerol to monoglycerides and may have an effect parallel to the solubility effects which result from an increase in process temperature. Consequently, a faster reaction at a lower temperature is expected. Moreover, some of the undesirable taste and color due to the decomposition of triglycerides at high temperatures may be eliminated. Biodiesel CO-product Cc-product recovery has always been a concern in the economics of the biodiesel 
process. The Lower phase from the vegetable oil transesterification process contains about $75 \%$ glycerol. Small amounts of esters, alcohol and impurities from soybean oil are also present. The conventional practice is to recover glycerol by distillation. An alternative for glycerol recovery is to convert the crude glycerol to its mono and di ester derivatives using triglycerides from vegetable oils (glycerolysis). The mono- and diglycerides can be made by the reaction of naturally occurring triglycerides, such as soybean oil. with glycerol. Mixtures of mono- and diglycerides with a small percentage of unreacted triglycerides will be formed. The purification step then follows (e.g. Alsop et al.: 1963; Birnbaum, 1959; Birnbaum \& Lederer. 1963). Therefore, in the co-product recovery flow chart, shown in Fig. 5: the first purification step will be eliminated. Please note that the impurities in the glycerol are practically the same impurities which are present in the soybean oil and will not interfere with the reactions involved. There are many commercial applications for the mixed monoand diglyceride products. Mono- and diglycerides are edible and find use as emulsifiers in foods and in the preparation of baked goods. A mixture of mono-, di- and triglycerides is manufactured in large quantities for use in super glycerinated shortenings. Mono- and diglycerides are important modifying agents in the manufacturing of alkyd resins, detergents and other surface-active agents. The monoglycerides are also used in the preparation of cosmetics, pigments. floor wax; synthetic rubbers, coatings, textiles, etc.

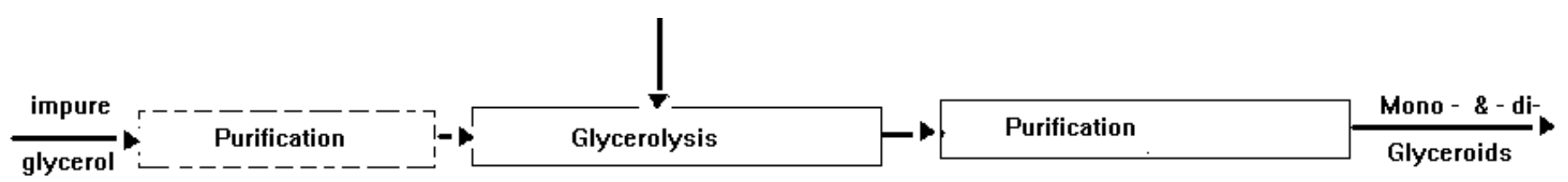




\section{CONCLUSIONS}

About 7.8 billion pounds of animal fats are produced annually in the U.S. After rendering this yields 5.5 billion pound of tallow and lard. Experimental investigations show that beef tallow can be easily esterified to components with properties similar to esters of vegetable oils. A blend of esters of fatty acids and diesel fuel will be helpful to the petroleum industry in meeting the new requirements for lower sulfur, aromatics and particulates in emissions from diesel engines. This will diversify the current tallow market. The high cost of biodiesel compared to petroleum diesel has been a major obstaclein the commercialization of biodiesel. Glycerol is the inevitable CO-product of transesterifing triglycerides to make fatty acid esters. While there is an existing market for glycerol, a significant increase in availability of glycerol resulting from the expanded use of triglycerides would destabilize the market considerably. Therefore, utilization of impure glycerol will make the biodiesel fuel more competitive with the existing diesel fuel market. The transesterification of triglycerides and glycerol involves two immiscible liquid phases. The degree of contact or solubility of these two phases limits the extent of the reaction. Temperature and reaction time may be reduced by enhancement of the contact between the immiscible liquid phases.

\section{ACKNOWLEDGEMENTS}

Authors express their gratitude to the U.S. Department of Agriculture Cooperative State Research Services and $\mathrm{t}$ h e Nebraska Soybean Board for their support of this work. 


\section{REFERENCES}

Alsop. W. G., Summit, N. J. \& Krems, I. J. (1963). Process for the preparation of higher fatty acid monoglycerides. US patent 3,083,216.

Birnbaum, H. (1959). Process for preparing monoglycerides of fatty acids. US patent 2,875,221.

Birnbaum, H. \& Lederer, J. (1963). Process for producing monoglycerides of fatty acids. US patent $3,102,129$.

Clark. S. I., Wagner, L., Schrock, M. D. \& Pinnaar, P. G. (1984). Methyl and ethyl ester as renewable fuels for diesel engines. JAOCS, 61 (IO), 16324.

Freemen. B.. Pryde, E. H. \& Mouns, T. L. (1984). Variables affecting the yield of fatty esters from transesterified vegetable oils. JAOCS. 61 110). 163843.

Kutlrt. N. H. (1951). Preparation of monoglicerides. US patent 2,634,279.

Mazel. M. A.. Summers, J. D. \& Batchelder, D. G. (1985). Peanut. soybean and cottonseed oil as diesel fuels. Trans. .4S.G. 28 (5). 1375-7.

Meffert. A. (1984)'. ' technical uses of fatty acid esters. JAOCS, 61 (2), 255-8.

Mittelbach, M. \& Tritthart. P. (1988). Diesel fuel derived from vegetable oils, 111. Emission tests using methyl esters of used fying oils. JAOCS. 65 (7)_ 1185-7.

Peterson. C. L., Wagner; G. L. \& Auld. D. L. (1983). Vegetable oil substitution for diesel fuel. Farrs. AS.\&. 26 (2), 322-7.

Peterson, G. L. (1986). Vegetable oil a diesel fuel: status and research priorities. $h n$ s ASAE, 29 (5). 1413-22.

Rheineck, A. E., Bergseth, R. \& Sreenivasan. B. (1968). Glycerolysis of linseed oil: a compositional study. JAOCS, 46: 447-51. 
Ryan 111, T. W., Dodge, L. G. \& Callahan. T. J. (1984). The effect of vegetable oil properties on injection and combustion in g o different' diesel engines. O C S6,1 (101, 1610-9.

Samson, W. D., Vidrine: C. G. \& D. Robbins, J. W. (1985). Chinese tallow seed oil as a diesel fuel extenders. Fans. ASAE. 28 (5). 1406-9.

Sankaran, V. (1990). transesterification of triglycerides. US patent 4,966,876.

Sonntag, N. 0 . V. (1982). Glycerolysis of fats and methyl esters-status, review, and critique. JAOCS, 59 (IO), 795A-802A.

Tanaka, Y., Okabe, A. \& Ando, S. (1981). Method for the preparation of a lower alkyl ester or fatty acid. US patent $4,303,590$.

Wright, H. J., Segur, J. B., Clark. H. V. C\% Coburn, S. K. (1944). A report on ester interchange. Oil and Soap J., 21,145-8. 